\title{
Superando desafios e preconceitos: rumo à universidade
}

\author{
José Ubiratan Sompré*
}

Minha trajetória de vida se resume em conquistar um lugar, no qual a diferença por ser indígena não seja vista como desigualdade por ser quem sou: Xerente, brasileiro, casado com uma Kaingang, pai de três filhos, discente do curso de Direito da Universidade Federal do Pará (UFPA), Campus de Marabá.

Hoje, com 37 anos de idade, acredito que tenho tempo suficiente para me dedicar aos estudos e futuramente contribuir para a conquista de direitos dos povos indígenas. $\mathrm{O}$ primeiro passo rumo à superação do desafio foi dado, estar em uma instituição que reconhece e oferece, por meio de ações afirmativas, a possibilidade de ingresso no ensino superior aos membros de povos indígenas.

Ao longo da vida, morei fora da aldeia, por circunstâncias alheias a minha vontade. Visto como índio desaldeado, sujeito "sem direito" e "integrado" à sociedade nacional, supostamente, como qualquer cidadão brasileiro, mas morando em favela e sofrendo diversas formas de discriminação pela condição de índio desaldeado. A vida fora da aldeia não é fácil, sem condições financeiras adequadas, muitos indígenas são desprezados e vivem em condições desumanas, sobrevivendo das sobras, num país tão rico em produção de alimentos.

Com o bom pescador e artesão que é meu pai, aprendi os segredos da pescaria e do artesanato, desde pequeno me embrenhava nas madrugadas por igarapés e rios para garantir o alimento do dia. No restante do tempo, fazia artesanatos para vender no comércio ou trocar por alimento. Pertenço a uma família grande, somos dez irmãos, sendo cinco homens e cinco mulheres. Meu pai, da etnia Xerente, saiu da aldeia muito cedo, com promessas de ser jogador de futebol, estudou até a quinta série e criou os filhos com integridade e honestidade. Sempre rígido na correção dos filhos, ensinou a importância do estudo para sobreviver fora da aldeia. Minha mãe, da etnia Guarani é mulher disposta e de grande coração, cresci vendo-a acolher

* Xerente, graduando em Direito pela Universidade Federal do Pará (UFPA), Campus de Marabá, Pará, Brasil. Bolsista do MEC, Programa Permanência/UFPA. E-mail: birasompre@hotmail.com

$$
\text { Tellus, ano 11, n. 20, p. 289-294, jan./jun. } 2011
$$

Campo Grande, MS 
parentes de diversas etnias e pessoas estranhas, em nossa casa. Conhecida por ser "benzedeira" é respeitada e considerada por muitos que a tomaram por comadre india.

Desde muito cedo, dividi o tempo de estudar com o tempo de trabalhar, minha atividade era produzir artesanato para comercialização; por longos anos, a venda dos artesanatos que eram produzidos em família garantiu o sustento. As dificuldades eram muitas, mas estava sempre presente na fala do meu pai a preocupação em manter os filhos longe das drogas e a importância de estudar.

Sempre procurávamos ajuda na Fundação Nacional do Índio (FUNAI) em busca de materiais escolares, mas o que nos diziam era que não tínhamos direito porque morávamos fora da aldeia e não estávamos no orçamento da Instituição. Os funcionários alegavam que deveríamos voltar a viver na aldeia se quiséssemos ser reconhecidos como indígenas e receber qualquer auxílio por parte do órgão indigenista ou nos submeter à realidade que tínhamos escolhido para viver: desaldeados.

Nos anos 1980, fomos morar na Aldeia Parkatêjê, na Reserva Indígena Mãe Maria, no hoje município de Bom Jesus do Tocantins, no estado do Pará. Apesar dos anos de convivência, éramos sempre vistos como "índios da cidade", por falar bem o português e não a língua do nosso povo. Diziam que não éramos "índios de verdade", mas "índios agregados" junto a um povo que, no momento oportuno, demonstrou que éramos, apenas, visita numa terra que não era a nossa. Depois de cinco anos, deixamos a aldeia e retornamos ao lugar de onde tínhamos saído, a cidade de Marabá.

Minha trajetória estudantil foi em escola pública, fora da aldeia. Uma das maiores dificuldades para estudar era adquirir o uniforme, algo obrigatório e, como éramos muitos irmãos, a despesa com materiais escolares era alta do ponto de vista econômico da família. Nesse período, as economias do lar eram obrigatórias, a confecção dos artesanatos era dobrada.

Morando de aluguel, em casas paupérrimas, conseguir o dinheiro para o pagamento, era um pesadelo, a cada final de mês. Mudávamos constantemente de casa por não poder pagar em dia o aluguel. A situação perdurou até meu pai adquirir um terreno numa invasão, onde construímos nossa casa.

O mesmo uniforme era usado por todos em idade escolar e por vários anos. Daí o porquê estudar sempre na mesma escola, para aproveitar o máximo possível o uniforme, comprado com muito custo. $\mathrm{O}$ material era bem aproveitado e aprendíamos a cuidar e valorizar o pouco que tínhamos. Nas idas à FUNAI em busca de ajuda, nossa mãe tinha sempre a mesma resposta, se sobrasse material poderiam nos fornecer, tudo porque não estávamos incluídos no orçamento da Instituição, somente os indígenas que moravam em aldeias tinham a preferência. 
Era humilhante ir à FUNAI por várias vezes para saber se a "sobra" de material escolar estava disponível. O contexto produzia reflexões que terminavam alimentando o ânimo para vencer e continuar estudando. Voltar à aldeia era a última escolha de meu pai, que sempre falava das dificuldades na cidade, pois dizia ele que, na aldeia Xerente, a fome e a impossibilidade de estudar se fariam presentes. Fome porque os recursos naturais eram escassos, somente a caça e a pesca não garantiriam o sustento de doze pessoas. A venda de artesanatos tornar-se-ia difícil devido à distância da cidade. O trabalho nas fazendas vizinhas era assemelhado ao escravo, portanto não teríamos melhores condições de vida. Quanto à educação oferecida pela FUNAI, na aldeia, era referente apenas às séries iniciais e em precárias condições. Cresci ouvindo que deveríamos voltar a morar na aldeia depois de formados. Meu pai sempre mantinha as lembranças da aldeia e contava as histórias do nosso povo. Alguns entre nós realizam o sonho de meu pai. Hoje, somos nove irmãos a morar em aldeias, não a nossa, mas as dos povos que nos acolhem pela formação que tivemos.

Voltando à situação enfrentada nas escolas da cidade, no período das comemorações de sete de setembro, mostrávamos um pouco da nossa cultura. Diziam que éramos atração das paradas, os "índios de verdade" desfilando pelas ruas de Marabá ao lado de alguns outros estudantes pintados à carvão, acorrentados, representando os negros e a escravidão. De igual modo, no Dia do Índio, hoje Dia dos Povos Indígenas, estávamos à disposição da escola para falar o que é ser índio. Sem poder falar em forma de protesto sobre as nossas dificuldades, falávamos o que todos queriam ouvir.

Para realizar o ensino médio, fui estudar na cidade de Castanhal, na Escola Agrotécnica Federal ${ }^{1}$. Por três anos morei na escola, sob o sistema de internato. Instituição onde se encontra hoje meu filho, realizando a possibilidade de cursar medicina, no futuro. No primeiro ano, eram muitos os comentários sobre minha forma de ingresso na instituição, diziam que só havia entrado por ser indígena e ter direito ao sistema de cotas, o que na opinião de muitos, havia excluído alguém que "de fato merecia a vaga" por ter feito o processo seletivo normal. No decorrer dos anos, fiz a minha parte, mostrando que tão importante quanto entrar era permanecer e sair formado. Fui escolhido, por mérito, como um dos melhores alunos da escola, o que não aconteceu com os muitos parentes indígenas, que desistiram no decorrer dos anos de estudo.

As dificuldades eram muitas em termos de assistência por parte da FUNAI, éramos esquecidos na Escola. A coordenadora de ensino do órgão indigenista não acompanhava a vida escolar dos indígenas estudantes.

\footnotetext{
${ }^{1}$ A Escola onde estudei talvez seja a Instituição mais antiga no Pará a acolher pessoas vunerabilizadas, na medida em que mantém o internato e oferece bolsa a elas. Mas os recursos são escassos, e nem todos conseguem o benefício.
}

Tellus, ano 11, n. 20, jan./jun. 2011 
Quando alguém adoecia, tínhamos que nos cuidar por conta própria. Muitas vezes, lavar a roupa dos amigos era a forma de ganhar alguns trocados para comprar produtos de higiene pessoal. Dos cinco indígenas que entraram na Escola, no ano em que ingressei, três desistiram devido à falta de condições básicas, como aquisição de produtos de higiene pessoal e material escolar. $\mathrm{O}$ baixo rendimento, a falta de acompanhamento pedagógico, as dificuldades de adaptação à vida fora da aldeia e a discriminação sofrida por ser indígena, significou a não permanência da maioria dos indígenas na escola. No conselho de professores, os indígenas eram sempre alvo de comentários e preocupações.

Depois de concluir o ensino médio, tornando-me Técnico Agrícola, mudei para Curitiba, no estado do Paraná, no intuito de prosseguir os estudos. Morei algum tempo com meu irmão mais velho, que havia casado com uma indígena da etnia Kaingang. Sem perspectivas de ingresso na universidade, mudei para a cidade de Chapecó, em Santa Catarina, onde uma de minhas irmãs, casada também com um Kaingang, residia. Na época, meu cunhado era administrador da FUNAI - Chapecó, e com promessas de emprego, passei a morar em Toldo Chimbangue, com os Kaingang. Foi quando conheci Rosani, minha mulher ${ }^{2}$. Depois de seis meses prestando serviço na aldeia sem ser contratado pela FUNAI e sem possibilidades de permanência, decidi sair de Toldo Chimbangue.

Casado e com a mulher grávida, passei a morar na Terra Indígena Xapecó a convite de Orides Belino Correia da Silva, liderança Kaingang. Foi na TI Xapecó que tive minha primeira experiência, como professor, e passei a lutar por educação escolar indígena de qualidade e que respeitasse as culturas indígenas. Juntamente com os demais professores indígenas, reivindicamos ao governo do Estado a construção de um complexo educacional adequado às especificidades arquitetônicas Kaingang, que culminou com a construção de uma escola, um centro de cultura e um ginásio de esportes na TI Xapecó.

Como professor de Artes, tinha uma sala de chão batido para fazermos fogo de chão e viver em sala a realidade dos estudantes, principalmente, nos dias frios de inverno. Lutamos e criamos a disciplina específica de cultura indígena na grade escolar.

Na TI Xapecó, passei a assessorar os trabalhos da liderança tradicional, fui membro do Conselho Tutelar, onde tentava mostrar que a tradição Kaingang na resolução de conflitos devia ser respeitada, o que nem sempre era considerado. Para ter acesso às condições básicas de saúde, educação, moradia e expressão política no município de Ipuaçu, a liderança indígena e

\footnotetext{
${ }^{2}$ Rosani de Fatima Fernandes, minha mulher, depois de anos de luta, tornou-se Mestre em Direito, pela Universidade Federal do Pará em 2010, na missão foi apoiada pelos Kyikatêjê povo junto ao qual vivemos - pela CAPES e pela Fundação Ford. Hoje, assessora as lideranças no encaminhamento de demandas.
} 
a comunidade se filiaram a um partido político, elegendo três vereadores e o vice-prefeito da etnia Kaingang, fato histórico considerando a relação desigual que era mantida com a comunidade na distribuição de recursos e participação na vida política do município. Infelizmente, no segundo ano de mandato, o então cacique e vice-prefeito Orides Belino Correia da Silva foi assassinado por motivos políticos, numa emboscada.

Como liderança, entre os Kaingang, participei da criação da Associação Indígena Kanhru (AIKA) que atua na defesa dos direitos Kaingang na TI Xapecó, a maior Terra Indígena do estado de Santa Catarina, com população de aproximadamente cinco mil indígenas. Fui coordenador de saúde da secretaria municipal, onde pude vivenciar as dificuldades do sistema público no trato com as especificidades culturais e linguísticas Kaingang.

Depois de dez anos de convivência com o povo de minha mulher, percebi que era hora de retornar ao Pará. Em 2004, a convite da liderança Kyikatêjê, passei a morar na Aldeia Kyikatêjê e assessorar a Associação Indígena Gavião Kyikatêjê Amtáti.

Quanto à formação superior, a falta de condições de ingresso e permanência e a incompatibilidade com os cursos ofertados pelas instituições particulares de ensino que mantinham convênio com a FUNAI, significaram 17 anos sem estudar, desde a conclusão do ensino médio em 1993. Por diversas vezes, prestei vestibular pelo sistema convencional junto a UFPA Campus de Marabá, sem sucesso. Hoje, com 37 anos, casado, com três filhos, ingressei pelo processo seletivo diferenciado que reserva duas vagas para povos indígenas em todos os cursos e campi da UFPA, no curso de Direito, no campus de Marabá, conforme mencionei.

Acredito que o ingresso no curso de Direito significa poder agregar novos conhecimentos às minhas experiências de vivência e luta pelos direitos dos povos indígenas. Desde muito cedo vivi a negação de direitos na pele, cresci e amadureci com a certeza de que posso fazer algo pela materialidade de direitos num país que sempre nos negou o direito de ser o quem somos: Xerente, Guarani, Kaingang, Karajá...

Pelas experiências adquiridas ao longo da minha trajetória de vida, acredito que o ingresso no curso de Direito é a possibilidade de compartilhar com os demais colegas de curso e professores a necessidade de respeitar os sistemas jurídicos próprios dos mais de 200 povos indígenas do Brasil, mostrar que tais direitos vão muito mais além do que as leis positivadas dizem e que é preciso conhecer a grande diversidade linguística e cultural dos povos indígenas, que devem ser respeitados nas suas especificidades. Minha trajetória de vida com certeza é a trajetória de muitos parentes desaldeados, mas ressalto que, em momento algum perdi a esperança em conquistar espaço num país de tantas adversidades e desigualdades. Tive muitas perdas, mas 
cada conquista valia à pena comemorar e muito tenho comemorado por ter ingressado no curso de Direito!

Recebido em 25 de setembro de 2010

Aprovado para publicação em 28 de novembro de 2010 